\title{
Frank Cole Spencer, MD
}

\author{
Richard J. Shemin, MD
}

The American Association of Thoracic Surgery bestows a lifetime Achievement Award from time to time on a member whose contributions to our specialty are outstanding and have left an indelible mark for future generations. The nominating committee, including the past 5 presidents, bestowed this highest degree of recognition to Dr Frank Cole Spencer.

Great talent and seminal contributions often spring from motivated individuals whose humble beginnings, extraordinary drive, and exquisite commitment to the pursuit of excellence lead to a career of the highest achievement. Malcolm Gladwell, ${ }^{1}$ author of Outliers: The Story of Success, has written about these individuals. Clearly, Frank Cole Spencer would be considered an outlier. His life and career illustrate the principles Gladwell has taught us.

Dr Spencer is quoted as saying, "I thank the good Lord for giving me a good brain, access to good education, and teachers who truly wanted me to succeed." He was born on a farm in rural Haskell County in West Texas. His role model was his paternal grandfather, a physician. The chances that this boy, educated by dedicated parents and schooled in a 2-room schoolhouse, would even go to college were against the odds. The determination of his parents to provide him with education and opportunity coupled with a high school science teacher who fueled his curiosity helped make his dreams a reality.

Dr Spencer entered North Texas State College as a freshman at the age of 15 years. Again, a great teacher and mentor, Dr James L. Carrico, chair of the department of chemistry, seeing great potential, chose "Frank" as his laboratory assistant. Spencer remembers, "His instilling the students with the excitement of learning and a warm paternalism, virtually adopting them as foster children." The combination of his teacher mentor and an innate desire for excellence, together with a farming background, made him "'an incurable workaholic.",

Dr Spencer entered Vanderbilt School of Medicine at the age of 17 years. Surgery beckoned him. He graduated (Alpha Omega Alpha) at the top of his class. The element of luck, a common component in great careers, was being in the right place at the right time. Clearly, becoming an

\footnotetext{
From the Division of Cardiothoracic Surgery, Department of Surgery, David Geffen School of Medicine at UCLA, and Ronald Reagan UCLA Medical Center, Los Angeles, Calif.

Received for publication Aug 31, 2009; accepted for publication Sept 4, 2009.

Address for reprints: Richard J. Shemin, MD, UCLA Surgery, 10833 Le Conte Ave-

nue, 61-182 CHS, Los Angeles, CA 90095 (E-mail: rshemin@mednet.ucla.edu).

J Thorac Cardiovasc Surg 2010;139:1-3

$0022-5223 / \$ 36.00$

Copyright (c) 2010 by The American Association for Thoracic Surgery

doi:10.1016/j.jtcvs.2009.09.004
}

intern at Johns Hopkins Hospital under Alfred Blalock, $\mathrm{MD}$, sparked an interest in the pioneering work in the new field of cardiac surgery. In addition, he was surrounded by the incredible collection of talented residents and faculty at Johns Hopkins working with Dr Blalock during this pivotal time in surgery.

After his internship year, Dr Spencer accompanied William Longmire, MD, to the University of California Los Angeles (UCLA) to the new Department of Surgery being developed. He worked clinically and in the laboratory with William Muller, MD, and James Maloney, MD. However, he left UCLA to serve in the United States Navy Medical Corp (1951-1953) during the Korean War.

Spencer's interest, curiosity, and dedication to his patients were a constant theme throughout his career. As a young surgeon at Hopkins and UCLA, he had learned how to repair arteries. Spencer was disappointed to see the typical clinical course of injury to the leg leading to gangrene and amputation, in part, because of the standard practice of arterial ligation of the injured vessel. Ligation was the treatment of choice since World War II because there was a long delay from injury to surgical treatment. In Korea, the Mobile Army Surgical Hospital unit with early evacuation by helicopter led to the opportunity for a change in practice by performing early arterial repair.

Seeking permission from the authorities to attempt repair of injured vessels on a trial basis was a seminal event in Spencer's career. After not receiving permission for several weeks, he faced court martial for proceeding to perform the repair of arterial injuries. During the next 9 months, more than 150 repairs were performed with an $80 \%$ to $90 \%$ success rate. The results were published in the Annals of Surgery. ${ }^{2}$

Spencer remarked, "I could not live with myself if I was forced to take someone's leg off when it was not necessary.", Instead of court martial, Spencer was given the Legion of Merit Award, which led to national recognition. "I became a boy hero, much to my embarrassment...but arterial repair in Korea benefited more people than anything I've ever done.'

After discharge, he returned to Johns Hopkins to complete his surgical residency under Dr Blalock. The Hopkins years included 6 years on the faculty where he developed into an innovative surgeon, a gifted teacher, and a mentor to students and residents. These were among the most innovative and exciting years in the development of the field of cardiac surgery.

In 1961, Spencer was recruited by Benjamin Eiseman, $\mathrm{MD}$, to become Professor of Surgery at the University of 
Kentucky. In 1966, he accepted the position as the George David Stewart Professor and Chairman of the Department of Surgery at New York University (NYU) School of Medicine. He served in that capacity for 32 years, producing one of the great surgical departments in clinical volume, innovative research, and superb residency training. Since 2002, he has remained active at his beloved NYU as Chairman of Clinical Facilities and Development and Director of Patient Safety.

Dr Spencer's wise council and leadership have resulted in his election by his peers to high office by several professional organizations in American Surgery. He was President of The Society of Clinical Surgery (1974-1975), New York Surgical Society (1976), Johns Hopkins Medical and Surgical Association (1994-1975), and New York Center for Liver Transplantation (1994). The most prestigious Presidential highlights include President of the American College of Surgeons (1990-1991), President of the American Association for Thoracic Surgery (1982-1983), and President of the American Surgical Association (1997-1998). His leadership was unparalleled as the Chairman of the Board of Regents of the American College of Surgeons (19871989) and by his outstanding work and leadership in the arena of professional liability. He was Chairman of the American College of Surgeons Regent's Professional Liability Committee (1985-1997).

Dr Spencer has never forgotten his Texas roots and dedication to each patient. He never delegated postoperative care to others. His clinical rounds were legendary for their attention to detail and logical scientific problem-solving. His morbidity and mortality conferences were unparalleled. Faculty and former residents have vivid memories of occasional fear and respect for this time-honored surgical conference. We were taught to understand outcomes, medical and technical errors of omission or commission, and knowledge gaps long before these concepts became formalized in "practice-based learning." Residents and faculty were always professional and prepared in his presence. His clinical judgment, experience, and knowledge of the medical literature were always current and innovative.

In the operating room, Dr Spencer was a master surgeon. His dedication to detail and compulsive recording of observations, which he later reviewed, allowed him to discover patterns that remained obscure to others. He always pushed the envelope to advance the safety and range of surgical treatments. He pursued perfection, teamwork, and communication, and demanded focused decorum during operations.

The advances in the field of surgery for coronary artery disease, valvular heart disease, myocardial preservation, mitral valve repair, and safe cardiopulmonary bypass have, in part, been due to his direct efforts or the efforts of those he stimulated to pursue these areas. For example, he sent George Green, MD, to the laboratory to investigate the use of the internal thoracic artery as a bypass conduit, an idea that he investigated during his Kentucky years. Dr Spencer sent O. Wayne Isom, MD, to work with Sir Bryan Barrett Boyes to bring his innovative surgical experience in congenital cardiac surgery to NYU. He was an early supporter of Gerald Buckberg, MD, and an early adopter of the clinical use of blood cardioplegia for myocardial protection. He sent Steven Colvin, MD, to Paris to learn Dr Carpentier's approach in techniques to mitral valve repair. He encouraged Joseph Cunningham, MD, to investigate spinal cord protection during descending thoracic aortic surgery. Dr Spencer understood the value of both basic and clinical research. He understood the power of large clinical databases and their contribution to outcomes research. He was the champion of the standard use of binocular magnifying loupes to perform coronary artery surgery.

Dr Spencer wrote more than 350 peer-review articles and 38 book chapters or books. Most notably, he was the coeditor of the annual Yearbook of Surgery from 1971 to 1991, Vascular Trauma (Rich and Spencer, editors), and Surgery of the Chest (5th and 6th editions, Gibbon, Sabiston, and Spencer, editors), and he was a founding editor of Schwartz's Principles of Surgery. Dr Spencer has lectured worldwide as a visiting professor. In 1997 he received the American Heart Association Achievement in Cardiovascular Science and Medicine Award.

Among all these achievements, awards, and professional recognition, Dr Spencer's greatest pride derives from teaching and enjoying the achievement of his medical students, residents, and fellows. The Hopkins traditions of clinical excellence, teaching, research, and leadership were the hallmarks of the NYU surgical experience. Dr Spencer was legendary for memorizing the face, name, and a brief biography of every intern. He influenced the surgical careers of hundreds of young surgeons, many of whom became chairman and leaders in surgery in the United States and abroad. He received the NYU School of Medicine Distinguished Teacher Award in 1969, 1970, and 1977, and the Torch of Learning Award from the American Friends of the Hebrew University in 1976.

He taught us his concepts of the basic principles of surgery. First and foremost he admonished, "Do what is best for the patient." This precept was epitomized in his career when he knew arterial repair was feasible and better than ligation. He boldly faced court martial while saving limbs, and eventually he changed military surgical policy. His second principle was, "Don't be smart enough to quit." This statement stems from the belief that all complex surgical problems have a cause often so difficult to figure out that most would give up. Spencer taught that persistence and using the scientific method with experimentation will eventually lead to solutions. "Surgery is a joy and the pleasure of a surgical career stems from several basic instincts. First is the deep instinctive personal pleasure in helping a sick person get better. Second is the excitement of intellectual 
productivity, the discovery of new knowledge, and the scientific basis of our profession. Third, is the pleasure of teaching, a vital [component] of the medical profession since the time of Hippocrates." Finally, "Unique to surgery is the creative use of one's hands to cure or improve human disease." His comments are timeless. Despite occasional failures, the surgeon's optimism, excitement, and pragmatic resourcefulness remain our strength throughout our careers as we seek surgical solutions to complex problems.

Dr Spencer's career has spanned over 4 decades. His contributions to general and vascular surgery, cardiac surgery, health policy, and surgical art and science are innumerable. His surgical expertise has saved tens of thousands of lives and relieved suffering. His impact on patient care is magnified by the hundreds of practicing surgeons he trained and influenced. Clearly, he stands among the giants of surgery in the twentieth century. His influence will be long lived through us, his students, residents, and colleagues. I am indebted to him as my teacher, mentor, role model, and lifelong advisor.

Dr Frank Cole Spencer's recognition by the American Association of Thoracic Surgery with this Lifetime Achievement Award honors him and brings distinction to our entire profession.

\section{References}

1. Gladwell M. Outliers: The Story of Success. New York, NY: Little, Brown and Company, Hachette Book Group; 2008.

2. Spencer FC, Grewe RV. The management of arterial injuries in battle casualties. Ann Surg. 1955;141:304. 